\title{
AC 2011-1714: A COMMUNITY COLLEGE PERSPECTIVE OF HOW OCEAN APPLICATIONS CAN ENHANCE TECHNICAL PROGRAM COURSE OF- FERINGS AND EXPAND STUDENT OPPORTUNITIES
}

\section{Scott Fraser, Long Beach City College}

Scott Fraser is the Department Chair of Electrical Technology at Long Beach City College. As the Chair, he is responsible for the largest community college Electrical Technology Program in California. The program has in excess of 730 students per semester in a 45 unit program that covers industrial electrical to CISCO Networking. He has been teaching since 1998.

Prior to LBCC, Scott was the President of Dolphin Scientific, Inc. for 12 years where the company developed a line of Digital Signal Processing platforms for both industrial and classified government applications. In addition to his work at DSI, Scott worked at Hughes Aircraft Company for 13 years going from Plant Electrician to Program Manager.

Scott has a BSEE from Cal State University, Los Angeles and his AS degree in Electrical Technology from Long Beach City College where he is currently teaching. 


\section{A Community College Perspective of How Ocean Applications Can Enhance Technical Program Course Offerings and Expand Student Opportunities}

The incorporation of ocean science applications into the electrical, electronic, computer science, and mechanical design programs provides the students with a real-world application for their course of studies and broadens their career opportunities. Further, giving students the hands-on applications first then following up with the technical concepts serves as a powerful motivator of student learning. The electrical technology program at the author's institution (California) is one example of how this can work. Students can enroll in a robotics applications class without prerequisites and as a result develop an immediate understanding of the operational systems. From there they demand additional knowledge on the inner workings of the systems providing selfmotivation for many of the theoretical classes. The goal for the students is to compete in the annual International ROV (Remotely Operated Vehicle) Competition and put their skills into practice.

The step to include ocean sciences into an existing technical program is a much smaller hurdle than trying to teach electrical or programming concepts to marine sciences students. The end result is an enhanced program, increased student retention, and a worldwide industry for student careers. The departmental implementation of this philosophy at the author's institution as well as student success and hiring's will be discussed.

\section{Problem Background}

Many community college electronics programs across the country are struggling to attract students and place those students into jobs or engineering degree programs. This was the case at the author's institution (XX College). In the 1998/99 school year, meetings were held to discuss ways to "reinvigorate" the electronics program.

Enrollment numbers were low, students completing the program were even fewer, jobs for electronic technicians with AA degrees were almost non-existent and the local engineering schools had moved most of their electronic classes to upper division, severely reducing transfer credits. A decision was made to retool the three-robotics classes that were part of the program, taking advantage of a donation of industrial robots from IBM. The thought was that if we could capture the student's interest in these classes, that increased interest might result in a higher retention rate as well as possible placement in jobs for robotics technicians.

Instructors were trained on the new equipment and students were used for the installation process in the classroom. As part of the class labs, students placed and connected the robots so that they could be used in class. These robots are four-axis pick-place robots from Seiko (now Epson). They required 220V AC, connection to computers and a sturdy foundation. Students were given short test programs to load 
into the robots and run once they came on line. As part of their labs, students performed all these tasks and one by one, the lab came to life with working robots. Students were provided with a top level system exposure to the robotic system and subsequent labs drilled down from there.

As the robots were being installed and as the semester progressed, the interest in the robotics lab increased by student word of mouth. Students also built supporting systems of conveyors and connection to Programmable Logic Controllers (PLC). With basic robotic cells built, students in subsequent semesters were challenged to complete various robotics applications; a miniature car paint line, billiard ball rack and stack application, chocolate spoon dipping line, vision system and part sorting. All of this had success, student interest and retention was increased, but something was missing. In discussing the situation with past students, the general comment was that they enjoyed the class but could not see themselves doing this type of work. The increased interest did not generate the results that were hoped for.

Turning Point

In the summer of 2003, the author had the opportunity to complete a weeklong underwater robotics-training course from the Marine Advanced Technical Education Center ${ }^{[1]}$ at Monterey Peninsula College. While the author was excited about the prospect of incorporating this material into the robotics classes, he had no idea the impact it would make on the students, the program, and to himself. To say things would never be the same is a wild understatement.

In Fall 2004, the lessons learned from the summer training were incorporated into the robotics class. Students signing up for the robotics class were informed of the change in instruction and surprisingly enough, all were excited about the prospects for the class. Rather than starting at lectures and series of labs, the top down concept of building an underwater robot was presented. In addition, the students were told that they would be competing with their robot at the end of the school year. The MATE Remotely Operated Vehicle (ROV) Competition ${ }^{[1]}$ specifications were utilized to gather the design parameters for the student's robot (ROV). This resulted in an application based understanding of the problem and then the design of systems to fulfill the requirements. First they had to understand what the ROV needed to accomplish, and then figure out how to make that happen. Students gravitated to groups depending upon their area of interest, electrical, software or mechanical design. Many had their hands in multiple areas.

The first ROV from XX College was a beast. Built with parts on hand, donated material, it was big and heavy, but it had all the necessary components. Propulsion systems, control systems, mechanical framing, buoyancy and task systems. The students made it into the water just prior to the competition and had almost no practice time. Essentially, Does the ROV leak? No; will the ROV move and operate? Yes; OK 
pack it and let's go. After arriving at the competition, the students discovered some transportation induced failures and had problems with their ROV. They were able to get it into the water and compete for some points. As their instructor, the author was surprised and quite pleased at the student's reaction and comments about the experience during the trip home from the competition.

\section{Student Success}

Student success can be measured in many ways. Standardized exams, completion of modules, retention and grades are all familiar measures. The best student success comes when it is self-motivated. Listening to the student's discuss their experiences at designing and building the ROV over the previous year and what they learned was a indication of student success that is hard to match. Each student stated that their placement in the competition did not matter to them, it was the journey over the past year and what they each had learned was important. Many of them stated that they had no idea that they were capable of such things. The following year, almost all of the students returned to the course to participate in the second year ROV even though they were not allowed to sign up for the course a second time (CA State rules for repeating a course). These students participated on their own time. This is a major indicator of program and student success.

\section{Ocean Science Applications}

The process of bringing an application into the classroom, the students learning that application from the top down is a way to engage students and place much of the learning process into their control. What differs here is the application. Ocean Science Applications in the form of underwater robotics is one that seems to capture the imagination of students of all ages and gender. Students love to build things that explore underwater. Much of underwater exploration is shrouded in mystery and areas that they know they will never go themselves. Simple student projects such as "Finding Nemo" with a ROV must not be dismissed. Whatever the reason, it is this author's experience that the area of underwater robotics appeals to a wide student base regardless of their exposure or familiarity with the ocean.

In response to the interest in the underwater robotics applications, changes were made to the course outlines and course delivery. Previously, the three-robotics classes had been prerequisite based. Two semesters of electronics or electrical courses were required, and then the classes had to be taken in sequence. During the initial years of incorporating underwater robotics into the courses, it was noticed that many of the students wanted to bring in friends that were interested in participating but did not have the prerequisite classes. Due to the changing nature of the class and the delivery method, prerequisite waivers were given out. Every student that requested a waiver ended up being successful in the class due application-based aspect of the learning process. 
The next step was to rewrite the course outlines to reflect the changing dynamics of the three courses. The decision was made to remove all the course prerequisites as part of the rewrite. In this rewrite, an engineering model was used of design, integration and application. Students could drop in at any of the three engineering phases. The fall semester focuses on system design. The spring semester is integration of those designs into a working system, making modifications as needed. Finally, the summer semester is application based, where students explore the further use of a system that is already designed and built.

In the fall, students are taught how to use the following tools.

1. EagleCad for circuit board layout. They are provided with a completed schematic and taught how to design and layout circuit boards

2. Solidworks concepts. Mechanical design for parts and systems is covered

3. Basic Programming. Previous years have used Microchip PIC processors and PicBasic. In 2010, Parallax Propeller processor and it's SPIN language was introduced. The Parallax environment is far superior to the PIC development environment making for easier learning by non-computer science students. Basic designs are completed, in addition soldering concepts and wiring concepts are taught. By the end of the semester, all of the ROV systems are designed with a rough mechanical design based upon student parameters is completed.

In the spring, students (returning and new) are charged with building their designs and integrating them with each other. New students work along side returning students and learn the systems as they proceed. Some of the new students report that they felt overwhelmed and a little behind at the start, but that they were able to quickly adapt and make significant contributions to the ROV as the semester progressed. One learning tool that is utilized is the requirement to post weekly status reports to the course online forum. Students are able to read reports from classmates and problems are discussed. One student commented that when he saw others in the class having the same problem as him, he felt relieved and worked through the uncertainty.

In the summer, the course is offered in a 2 week, 5 day per week, 7 hrs per day format. Recruitment notices are sent out to local high schools and the course is used to introduce underwater robotics concepts to high school students and college students who want to "get their feet wet". Many of the returning students participate in the class and act as group leaders. The course covers one week of "industrial robotics" utilizing the Epson robots and one week of underwater robotics utilizing the student built ROVs. An indicator of the student engagement level in the summer class is that they have to be ushered out for a lunch break while the lab is closed. Aside from the short lunch break, students work straight through the morning and afternoon sessions without requesting breaks. It is known that they can take breaks as needed, but nobody ever seems to go on one. 


\section{Competition Participation}

Each student's participation in the MATE ROV competition is optional and not part of his or her grade. Even though this is the case, most of the students in the class find themselves participating in the project after class hours in one form or another. The lab is available for students to come in and work outside of class hours Monday through Saturday. It is easier to count the unoccupied lab time verses when students are present and working on projects. The competition requirements also provide milestones and work product that is expected out of each student. The competition requires a technical report and technical display along with a verbal technical presentation from each team in the competition. All three of these become required parts of the course. Students are tasked with writing papers that describe the design rationale behind their product. Each student writes about the sub-system they designed and/or built. Those reports are then used as the starting point for the technical report and display for the competition. The students are also required to make a five-minute oral presentation to the class about their sub-system as a precursor to the competition technical presentation. In the fall semester, students are asked to present their designs to the class as part of the design review process, opening up the student to comments and questions from their classmates.

Results

The results of using underwater robotics have far exceeded those when the courses focused on industrial (land based) robotics. Students make immediate connections to the ocean applications. For many, they do not have any connection to a robot assembling parts, but can easily latch onto the idea of an underwater robot performing work and/or research. Since the incorporation of underwater robotics and the MATE ROV competition into the electrical program at XX College, the changes have been numerous.

1. The demand for the course has increased; Class size varies from 25 to 35 students per semester on word of mouth advertising only.

2. Students from outside the electrical department have taken the course; many have switched majors and now have completed the 45-unit Electrical Technology certificate and degree program.

3. The number of women students involved has dramatically increased; typical number of women in electrical classes is zero or sometimes one and it has been typical to have as many as four or five women involved in the class per semester.

4. Students are now transferring in addition to getting their certificate or degree; UC San Diego, Cal Poly Pomona, CSU Long Beach, Berkeley and US Navy Nuclear Engineering are just a few of the transfer locations.

5. Employers for hire now seek XX College students out. Some of the employers include: Oceaneering ${ }^{[3]}$ (world's largest underwater robotics company), Port of 
Long Beach, Port of Los Angeles, Underwater Systems, MGM Transformers, Millenworks, and Woods Hole Oceanographic Institute.

6. XX College students were directly involved in the operations to secure the BP well head disaster in 2010. Three graduates of the program worked endless hours operating their ROVs both working and providing video feeds to the world.

7. Connections have been made with the underwater archaeology program at XX College with students in both programs participating in joint events. Some of the archaeology students have successfully enrolled in and have completed the robotics courses. Others after completed the robotics courses have stayed on and completed the entire 45 unit electrical program changing the direction of their career. Electrical students having been exposed to the archaeological applications have enrolled in archaeology courses as Associate Degree electives.

8. XX College students have placed $1^{\text {st }}$ or $2^{\text {nd }}$ three years in a row at the MATE International ROV competition ${ }^{[1]}$.

9. XX College students have been selected for numerous MATE internships gaining at-sea experience in underwater applications. Recent interns include one who worked on the Deepwater Horizon summer of 2009 and in 2010 one who was at sea with Dr. Robert Ballard's research vessel Nautilus ${ }^{[3][4]}$ while they explored hydrothermal vents off of Greece.

10. XX College students regularly demonstrate their ROV while doing presentations to the public and piloting it in the local aquarium's reef exhibit in support of the Aquarium's and NOAA's technical outreach programs.

11. The 2006 ROV is part of the Hydrothermal Vent Exhibit at the California Science Center in Los Angeles ${ }^{[5]}$.

12. XX College working with the MATE center is entering its second year of outreach to middle schools and bringing underwater robotics to the middle school and high school level. In 2010, local five middle schools incorporated underwater robotics as part of their after-school programs and in 2011 and additional five schools have been added. The student excitement level at the middle school level is just as high as observed at the college level. The involvement of female student in STEM activities is well beyond hopes. As part of this activity, XX College robotics students are paired with a middle school and help the middle school teacher teach robotic concepts to the students. This is yet another outside of class activity.

\section{Conclusion}

There a many terms for the type of learning discussed here; Application Based Learning, Problem Based Learning, Problem Solving Learning. These are not new and are accepted learning methods. What sets this apart from others is the application that is used; Ocean Sciences or underwater robotics. The results of incorporating ocean sciences applications into an open (no prerequisites) series of robotics courses has the potential to capture the imagination and efforts of students resulting in careers and further education opportunities. The amount of work that it takes for an electronics 
instructor to become trained on underwater applications is minimal versus the mountain of work for a marine science program to incorporate electronics, programming, mechanical design concepts into their marine program. The opportunity for program growth, student careers and instructor rewards is enormous. When presented with an application that captures their imagination, students want to learn. That makes our job as instructors that much easier; not to mention fun.

\section{Bibliography}

1. MATE International ROV Competition http://www.materover.org

2. Oceaneering International http://www.oceaneering.com

3. Nautilus Research Vessel http://www.nautiluslive.org

4. The Jason Project http://www.jason.org/public/whatis/start.aspx

5. California Science Center Hydrothermal Vent Exhibit http://www.californiasciencecenter.org/Exhibits/WorldOfEcology/ExtremeZone/ExtremeZone.php 